\title{
REVERSE-PHASE HIGH-PERFORMANCE LIQUID CHROMATOGRAPHY METHOD DEVELOPMENT AND VALIDATION FOR SIMULTANEOUS ESTIMATION AND FORCED DEGRADATION STUDIES OF EMTRICITABINE, RILPIVIRINE, AND TENOFOVIR ALAFENAMIDE IN SOLID DOSAGE FORM
}

\author{
JULURI KRISHNA DUTTA TEJASWI ${ }^{1 *}$, GOVINDA RAJAN R ${ }^{2}$ \\ ${ }^{1}$ Department of Pharmaceutical Analysis, College of Pharmaceutical Sciences, Acharya Nagarjuna University, Guntur, Andhra Pradesh, \\ India. ${ }^{2}$ Department of Pharmaceutical Chemistry, Hindu College ofPharmacy, Guntur, Andhra Pradesh, India. Email: y2kteja@gmail.com
}

Received: 01 August 2018, Revised and Accepted: 04 September 2018

ABSTRACT

Objective: A stability indicating reverse-phase high-performance liquid chromatography (RP-HPLC) method was developed and validated for the estimation of emtricitabine (EMT), rilpivirine (RIL), and tenofovir alafenamide (TAF) in combined dosage forms and its API.

Methods: Chromatographic separation was achieved on Waters ACQUITY RP-HPLC with PDA detector having Zodiac C18 Column $(250 \times 4.6 \times 5 \mu)$ using mobile phase mixture of phosphate buffer: acetonitrile in the ratio of 40:60 v/v at $262 \mathrm{~nm}$.

Results: The assay was performed with tablets, and the \% assay was found to be 100.104 for EMT, 99.74 for RIL, and 102.41 for TAF which shows that the method is useful for routine analysis. The linearity was found to be linear with a correlation coefficient of 0.999 , which shows that the method is capable of producing good sensitivity. The retention time (RT) of EMT, RIL, and TAF using optimum conditions was found to be 2.517, 3.273 , and $6.697 \mathrm{~min}$. Forced degradation studies (FDS) were performed on sample using acid, base, thermal, photolytic, and peroxide degradation.

Conclusion: Due to its simplicity, rapidness, high precision, and low RT value, this method was successfully applied to the estimation of EMT, RIL, and TAF combined dosage form. The drugs were found to be stable at FDS, and the net degradation was found to be within the limits.

Keywords: Rilpivirine, Emtricitabine, Tenofovir alafenamide, Reverse-phase high-performance liquid chromatography.

(c) 2019 The Authors. Published by Innovare Academic Sciences Pvt Ltd. This is an open access article under the CC BY license (http://creativecommons. org/licenses/by/4. 0/) DOI: http://dx.doi.org/10.22159/ajpcr.2019.v12i1.28765

\section{INTRODUCTION}

Emtricitabine (EMT) [1-3] is a nucleoside reverse transcriptase inhibitor (NRTI) for the treatment of HIV infection in adults which works by inhibiting reverse transcriptase, the enzyme that copies HIV RNA into new viral DNA, resulting in early chain termination. Its chemical name is 5-fluoro-1-[(2R, 5S)-2-(hydroxymethyl)-1, 3-oxathiolan-5-yl] cytosine and the molecular formula is $\mathrm{C}_{8} \mathrm{H}_{10} \mathrm{FN}_{3} \mathrm{O}_{3} \mathrm{~S}$.

Tenofovir alafenamide (TAF) [4-8] is a NRTI and a novel ester prodrug of the antiretroviral tenofovir. Its chemical name is ( $\{[(2 \mathrm{R})-1-(6-a m i n o-$ 9H-purin-9-yl)propan-2-yl]oxy\}methyl) phosphoric acid and the molecular formula is $\mathrm{C}_{21} \mathrm{H}_{29} \mathrm{~N}_{6} \mathrm{O}_{5} \mathrm{P}$.

Rilpivirine (RIL) [9] is non-NRTI (NNRTI) which is used for the treatment of HIV-1 infections in treatment-naive patients. RIL is a noncompetitive NNRTI that binds to reverse transcriptase. Its chemical name is $\quad 4-\{[4-(\{4-[(1 \mathrm{E})-2$-cyanoeth-1-en-1-yl]-2,6-dimethylphenyl $\} a m i n o)$ pyrimidin-2-yl]amino\}benzonitrile and the molecular formula is $\mathrm{C}_{22} \mathrm{H}_{18} \mathrm{~N}_{6}$.

According to literature survey, there was no official method for the simultaneous estimation of EMT, RIL, and TAF, but only few reversephase high-performance liquid chromatography (RP-HPLC) [10-12] methods have been described in the literature for individual or in combination with other drugs for the estimation which were found to have high retention time (RT) and more total run time for analysis. There was no stability indicating analytical methods reported for simultaneous estimation of EMT, RIL, and TAF. The aim of the present work deals with the development of RP-HPLC method along with forced stability studies which was found to be simple, precise, accurate, and shorter RT which makes this method good for routine analysis in research institutions which justify that the developed method is advantageous over the existing method as per the ICH as shown in Fig. 1.

\section{METHODS}

\section{Chemical and reagents}

Pure samples were obtained from Hetero Pharma Ltd., Hyderabad, India; marketed formulation of combination was purchased from local market; tetrahydrofuran and acetonitrile (ACN) were obtained from Rankem, India Co. Ltd., methanol, water, and ammonium acetate were obtained from LiChrosolv (Merck), and potassium dihydrogen orthophosphate (ODP) was obtained from Molychem.

Buffer and mobile phase (MP) preparation

$17 \mathrm{~g}$ of ammonium acetate was taken in a volumetric flask and add $90 \mathrm{ml}$ of water in it and mix well and make up the volume to $100 \mathrm{ml}$ with water which was used as buffer.

The mixture of 40 volumes of $0.1 \mathrm{~N}$ ODP buffer and 60 volumes of ACN $(40: 60 \mathrm{v} / \mathrm{v})$ was prepared and sonicated for $10 \mathrm{~min}$ which was used as MP.

Standard and sample preparation

Weigh accurately $13 \mathrm{mg}$ of EMT, $1.62 \mathrm{mg}$ of RIL, and $20 \mathrm{mg}$ of TAF in $100 \mathrm{ml}$ of volumetric flask and dissolve in $10 \mathrm{ml}$ of MP and make up the volume with MP. From that, $13 \mu \mathrm{g} / \mathrm{ml}$ of EMT, $1.62 \mu \mathrm{g} / \mathrm{ml}$ of RIL, and $20 \mu \mathrm{g} / \mathrm{ml}$ of TAF was prepared by diluting $5.3 \mathrm{ml}-10 \mathrm{ml}$ with MP which was used as stock solution.

5 tablets were weighed and taken into a mortar and crushed to fine powder and uniformly mixed. Weight equivalent to $34.62 \mathrm{mg}$ and dissolved. Further dilutions were prepared in five replicates of $13 \mu \mathrm{g} / \mathrm{ml}$ of EMT, $1.62 \mu \mathrm{g} / \mathrm{ml}$ of RIL, and $20 \mu \mathrm{g} / \mathrm{ml}$ of TAF which were 
made by adding $5.3 \mathrm{ml}$ of stock solution to $10 \mathrm{ml}$ of MP which was used as sample solution.

\section{Instrumentation}

The separation was carried out on Waters Acquity RP-HPLC with PDA detector having Empower 2 software with Zodiac C18 Column $(250 \times 4.6 \times 5 \mu)$, Nicolet Evolution $100 \mathrm{UV} /$ visible, METSAR pH meter, POWERSONIC 405 sonicator, Afcoset er-200a analytical balance and pipettes, beakers, and burettes made of borosil were used.

\section{Method validation [13-15]}

The analytical method was validated with respect to parameters such as linearity, limit of quantification (LOQ), limit of detection (LOD), precision, accuracy, selectivity, recovery, and ruggedness.

\section{Forced stability studies}

Preparation of solution

Weight equivalent to 1 tablet, i.e., $200 \mathrm{mg}$ of EMT, $25 \mathrm{mg}$ of RIL, and $25 \mathrm{mg}$ of TAF into $50 \mathrm{ml}$ capacity standard volumetric flask. The contents in the flask were dissolved using methanol and sonicate it and diluted up to the mark with methanol.

\section{Acid degradation condition}

Accurately $5.0 \mathrm{ml}$ aliquot of above stock solution was transferred into a $50 \mathrm{ml}$ round bottom flask, and $2.5 \mathrm{ml}$ of $0.1 \mathrm{~N} \mathrm{HCl}$ was added. The flask was refluxed at $60^{\circ} \mathrm{C}$ for $30 \mathrm{~min}$ using evaporator and then allowed to cool. Then neutralize with $0.1 \mathrm{~N} \mathrm{NaOH}$ solution. Using MP, finally volume was made up to the mark and percentage of degradation was calculated.

\section{Alkali degradation condition}

Accurately $5.0 \mathrm{ml}$ aliquot of above stock solution was transferred into a $50 \mathrm{ml}$ round bottom flask, and $2.5 \mathrm{ml}$ of $0.1 \mathrm{~N} \mathrm{NaOH}$ was added. The flask was refluxed at $60^{\circ} \mathrm{C}$ for $30 \mathrm{~min}$ using evaporator and then allowed to cool. Then neutralize with $0.1 \mathrm{~N} \mathrm{HCl}$ solution. Finally, volume was made up to the mark with MP, and percentage of degradation was calculated.

\section{Thermal induced degradation condition}

$200 \mathrm{mg}$ of EMT, $25 \mathrm{mg}$ of RIL, and $300 \mathrm{mg}$ of TAF were weighed accurately and transfer into four different Petri dishes and kept in a hot air oven for $8 \mathrm{~h}$ at $105^{\circ} \mathrm{C}$. The content in the flasks was dissolved using methanol and diluted up to the mark with methanol, and the percentage of degradation was calculated.

\section{Photolytic degradation condition}

A $5 \mathrm{ml}$ aliquot of above stock solution was exposed to sunlight for about $6 \mathrm{~h}$ and then the sample diluted with $5 \mathrm{ml}$ of MP, and percentage of degradation was calculated.

\section{Peroxide degradation condition}

Accurately $5.0 \mathrm{ml}$ aliquot of above stock solution was transferred into a $50 \mathrm{ml}$ round bottom flask, and $3.0 \mathrm{ml}$ of $3 \% \mathrm{H}_{2} \mathrm{O}_{2}$ was added. The flask was kept at room temperature for $30 \mathrm{~min}$ then allowed to cool. Finally, volume was made up to the mark with MP, and the percentage of degradation was calculated.

\section{RESULTS AND DISCUSSION}

For selecting column chiral columns of OD52546 and SCDP52546, Inertsil was chosen to separate EMT, RIL, and TAF by injecting system

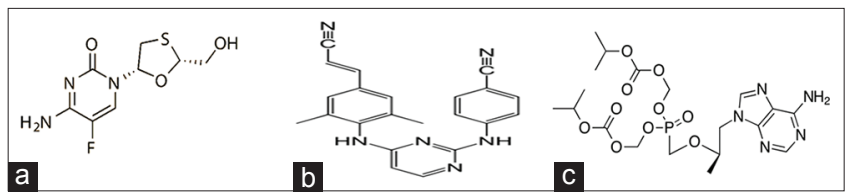

Fig. 1: Chemical structure of (a) emtricitabine, (b) rilpivirine, and (c) tenofovir alafenamide suitability solution with the MP at $1.0 \mathrm{ml} / \mathrm{min}$ individually. Various solvents including water, ACN, triethyl amine, ammonium acetate, and methanol were used in different combinations to get good peaks resolutions and lesser runtime. Different flow rates from 0.4 to $1 \mathrm{ml} / \mathrm{min}$ in gradient mode have been studied to achieve a good peak resolution. The column temperature was set at $25^{\circ}, 30^{\circ}$, and $35^{\circ} \mathrm{C}$ for optimizing according to its effect on peak resolutions and RT of the drug samples. After performing several trails with various combinations of Methanol, ACN and buffer, an sharp and well resolved peaks were obtained using MP of $0.01 \mathrm{~N}$ phosphate buffer (pH:4):ACT in the ratio of 40:60 V/V. Under above-described experimental conditions, all the peaks were well defined and free from tailing.

\section{System suitability}

The RT of EMT, RIL, and TAF using optimum conditions was 2.517, 3.273 , and $6.697 \mathrm{~min}$, respectively. The peak symmetries were $<1.5$, theoretical plates were $>2000$, and \% relative standard deviation (RSD) was $<2$ as shown in Table 1 .

\section{Specificity}

The specificity of the method was evaluated using placebo solution and a blank solution. Optimized chromatogram of EMT, RIL, and TAF is shown in Table 2 and Figs. 2-3.

Table 1: System suitability results of EMT, RIL, and TAF

\begin{tabular}{llll}
\hline Parameter & EMT & RIL & TAF \\
\hline Peak area & 1012865 & 1105605 & 1118501 \\
Theoretical plates & 2862.66 & 6433 & 6402.16 \\
Retention time (min) & 2.517 & 3.273 & 6.697 \\
Tailing factor & 0.96 & 1.22 & 1.335 \\
\hline
\end{tabular}

EMT: Emtricitabine, RIL: Rilpivirine, TAF: Tenofovir alafenamide

Table 2: Results of assay of EMT, RIL, and TAF

\begin{tabular}{llll}
\hline Injection & EMT & RIL & TAF \\
\hline Average area & 1079.485 & 1087.21 & 1744.953 \\
Label claim (mg) & 200 & 25 & 25 \\
Amount found (mg) & 200.08 & 24.93 & 25.60 \\
Assay (\%) & 100.04 & 99.74 & 102.41 \\
\hline
\end{tabular}

n=6; EMT: Emtricitabine, RIL: Rilpivirine, TAF: Tenofovir alafenamide

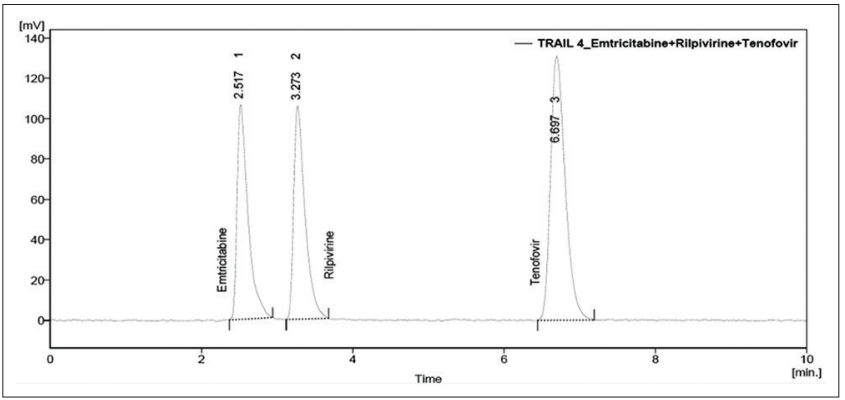

Fig. 2: Optimized chromatogram of emtricitabine, rilpivirine, and tenofovir alafenamide

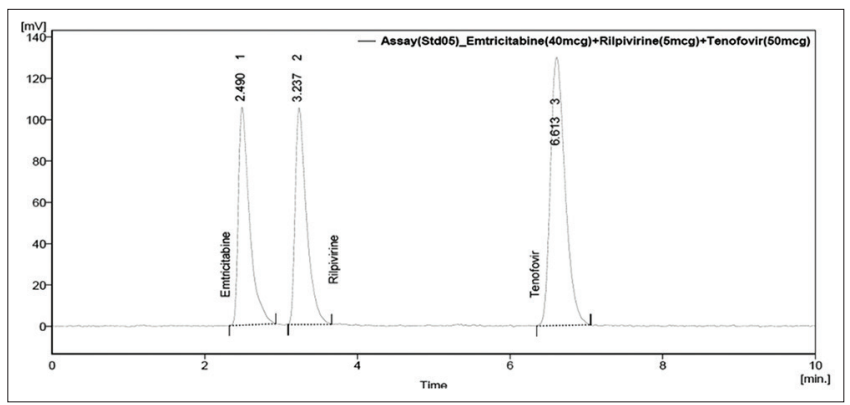

Fig. 3: Assay chromatogram of emtricitabine, rilpivirine, and tenofovir alafenamide 
Linearity

Weight accurately $13 \mathrm{mg}$ of EMT, $1.62 \mathrm{mg}$ of RIL, and $20 \mathrm{mg}$ of TAF in $100 \mathrm{ml}$ of volumetric flask and dissolve in $10 \mathrm{ml}$ of MP and make up the volume with MP. From the above stock solution, $13 \mu \mathrm{g} / \mathrm{ml}$ of EMT, $1.62 \mu \mathrm{g} / \mathrm{ml}$ of RIL, and $20 \mu \mathrm{g} / \mathrm{ml}$ of TAF were prepared by diluting $5.3 \mathrm{ml}-10 \mathrm{ml}$ with MP as shown in Table 3 and Figs. 4-6. The correlation coefficient for linear curve obtained between concentration and area for standard preparations of EMT, RIL, and TAF is 0.997, 0.993, and 0.995 .

\section{System precision}

The system precision of the proposed method was determined by analyzing the corresponding responses for three different days over a period of 1 week. One dilution of all the drugs in six replicates was injected into HPLC system and was analyzed as shown in the Table 4.

\section{LOD and LOQ}

LOD values for EMT, RIL, and TAF were $0.75,0.253$, and $0.253 \mu \mathrm{g} / \mathrm{ml}$ with signal-to-noise ratios of 3:1. LOQ values for EMT, RIL, and TAF were $2.254,0.74$, and $2.524 \mu \mathrm{g} / \mathrm{ml}$ with signal-to-noise ratios of 10:1.

\section{Method precision}

Precision was expressed as the closeness of agreement between a series of measurements obtaining from multiple sampling of the same homogeneous sample. Prepare sample preparations of EMT, RIL, and TAF as per test method and inject 6 times into the column as shown in Table 5.

\section{Ruggedness}

The ruggedness of the method was studied by the determining the analyst-to-analyst variation by performing the assay by two different analysts. The \% RSD of assay values between two analysts should not be $>2.0 \%$. Results were found within the acceptance limits (RSD $<2)$ as shown in Tables 6.

\section{Accuracy}

Accuracy of the method was determined by recovery studies. To the formulation (pre-analyzed sample), the reference standards of the drugs were added at the level of $50 \%, 100 \%$, and $150 \%$. The recovery studies were carried out 3 times and the percentage recovery and percentage mean recovery were calculated for drug as shown in Table 7. The percentage mean recovery of EMT, RIL, and TAF is $100 \%$, $101 \%$, and 99\%, respectively. The results are given in Table 7.

\section{Robustness}

To demonstrate the robustness of the method, prepare solution as per the test method and inject at different variable conditions using different conditions such as temperature and wavelength. System suitability parameters were compared with that of method precision. The result of the robustness study of the developed assay method is established in Table 8.

\section{Forced stability studies}

The stability studies were determined by applying the physical stress to the product. It was observed that there was marked degradation in the chromatograms. Results of forced degradation studies are shown in Table 9 and blank for control is recorded. Degradation studied was performed under different conditions, and in each condition, it was

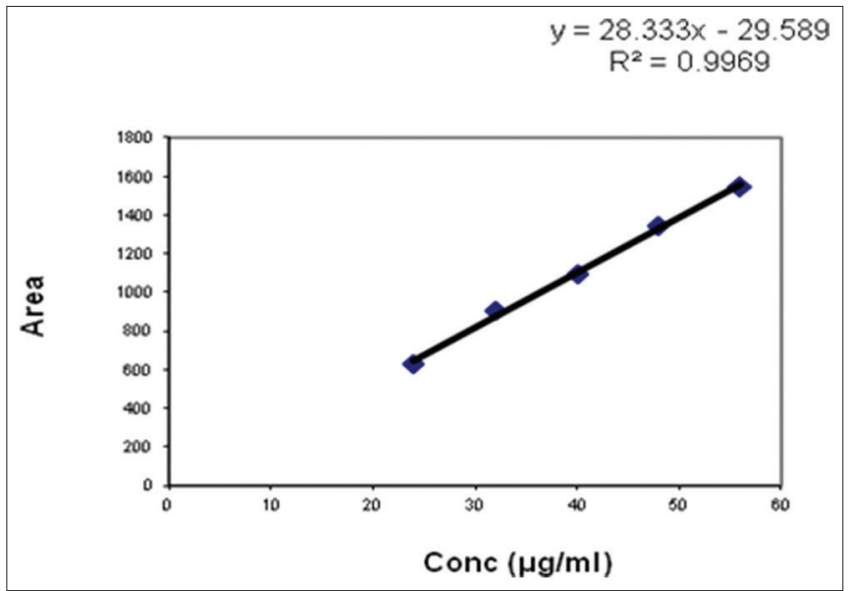

Fig. 4: Linearity graph of emtricitabine

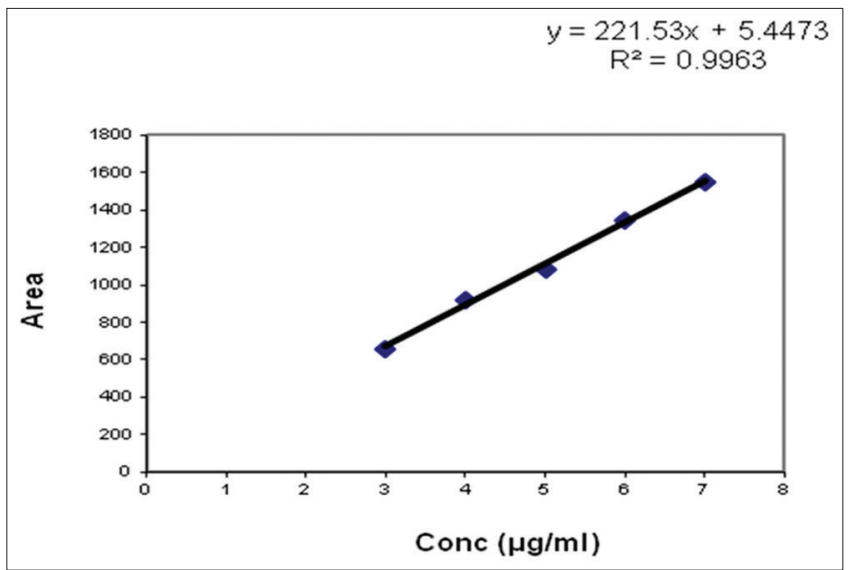

Fig. 5: Linearity graph of rilpivirine

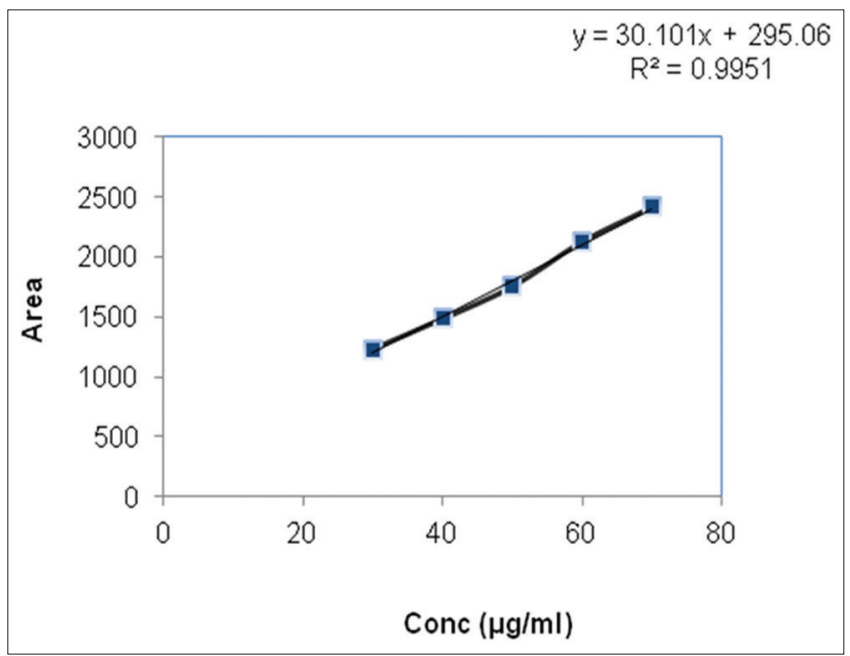

Fig. 6: Linearity graph of tenofovir alafenamide

Table 3: Linearity data of EMT, RIL, and TAF.

\begin{tabular}{|c|c|c|c|c|c|}
\hline \multicolumn{2}{|l|}{ EMT } & \multicolumn{2}{|l|}{ RIL } & \multicolumn{2}{|l|}{ TAF } \\
\hline Concentration $(\mu \mathrm{g} / \mathrm{ml})$ & Peak area & Concentration $(\mu \mathrm{g} / \mathrm{ml})$ & Peak area & Concentration $(\mu \mathrm{g} / \mathrm{ml})$ & Peak area \\
\hline 24 & 631.586 & 3 & 659.236 & 30 & 1229.584 \\
\hline 32 & 907.713 & 4 & 919.393 & 40 & 1482.509 \\
\hline 40 & 1091.004 & 5 & 1086.050 & 50 & 1750.266 \\
\hline 48 & 1339.312 & 6 & 1348.518 & 60 & 2124.626 \\
\hline 56 & 1549.123 & 7 & 1552.332 & 70 & 2413.579 \\
\hline
\end{tabular}

n=5; EMT: Emtricitabine, RIL: Rilpivirine, TAF: Tenofovir alafenamide 
Table 4: System precision data of EMT, RIL, and TAF

\begin{tabular}{|c|c|c|c|c|c|c|}
\hline \multirow[t]{2}{*}{ S. No } & \multicolumn{2}{|l|}{ EMT } & \multicolumn{2}{|l|}{ RIL } & \multicolumn{2}{|l|}{ TAF } \\
\hline & Retention time (min) & Peak area & Retention time (min) & Peak area & Retention time (min) & Peak area \\
\hline Average & 2.5190 & 1078.909 & 3.273 & 1088.830 & 6.700 & 1748.044 \\
\hline$\%$ RSD & 1.39 & 1.39 & 0.10 & 1.35 & 0.12 & 1.50 \\
\hline
\end{tabular}

n=3; EMT: Emtricitabine, RIL: Rilpivirine, TAF: Tenofovir alafenamide. RSD: Relative standard deviation

Table 5: Method precision data of EMT, RIL, and TAF

\begin{tabular}{|c|c|c|c|c|c|c|}
\hline \multirow[t]{2}{*}{ S. No } & \multicolumn{2}{|l|}{ EMT } & \multicolumn{2}{|l|}{ RIL } & \multicolumn{2}{|l|}{ TAF } \\
\hline & Retention time (min) & Peak area & Retention time (min) & Peak area & Retention time (min) & Peak area \\
\hline Average & 2.5190 & 1078.909 & 3.273 & 1088.830 & 6.700 & 1748.044 \\
\hline SD & 0.0024 & 14.836 & 0.003 & 14.708 & 0.008 & 22.745 \\
\hline$\%$ RSD & 0.10 & 1.38 & 0.10 & 1.35 & 0.12 & 1.30 \\
\hline
\end{tabular}

$\mathrm{n}=6$; EMT: Emtricitabine, RIL: Rilpivirine, TAF: Tenofovir alafenamide, RSD: Relative standard deviation

Table 6: Ruggedness data of EMT, RIL, and TAF

\begin{tabular}{llll}
\hline Sample & EMT & RIL & TAF \\
\hline Analyst 1 & 100.86 & 100.479884 & 100.723731 \\
Analyst 2 & 99.97565 & 100.51467 & 99.1048846 \\
\hline
\end{tabular}

EMT: Emtricitabine, RIL: Rilpivirine, TAF: Tenofovir alafenamide

Table 7: Recovery data of EMT, RIL and TAF

\begin{tabular}{llllll}
\hline Drug & Sample (\%) & Amount (mg) & Area & \% Mean & \% Average \\
\hline EMT & 50 & 32 & 930.06 & 102.87 & 100.19 \\
& 100 & 40 & 1050.7 & 99.6 & \\
\multirow{2}{*}{ RIL } & 150 & 48 & 1300.2 & 98.1 & \\
& 50 & 4 & 930.02 & 102.52 & 101.3 \\
& 100 & 5 & 1085.1 & 99.08 & \\
TAF & 150 & 6 & 1380.5 & 102.5 & \\
& 50 & 40 & 930.02 & 99.21 & 99.7 \\
& 100 & 50 & 1085.1 & 101.28 & \\
\hline
\end{tabular}

n=3; EMT: Emtricitabine, RIL: Rilpivirine, TAF: Tenofovir alafenamide

Table 8: Robustness results of EMT, RIL, and TAF

\begin{tabular}{|c|c|c|c|c|c|c|}
\hline \multirow[t]{2}{*}{ Parameter } & \multicolumn{2}{|c|}{ EMT } & \multicolumn{2}{|c|}{ RIL } & \multicolumn{2}{|c|}{ TAF } \\
\hline & Rt (min) & Tf & Rt (min) & Tf & Rt (min) & Tf \\
\hline \multicolumn{7}{|l|}{ Flow rate } \\
\hline $1.0 \mathrm{ml} / \mathrm{min}$ & 2.987 & 1.338 & 3.880 & 1.676 & 7.893 & 1.525 \\
\hline $1.4 \mathrm{ml} / \mathrm{min}$ & 2.167 & 1.758 & 2.810 & 1.354 & 5.700 & 1.550 \\
\hline \multicolumn{7}{|l|}{ Wavelength } \\
\hline $260 \mathrm{~nm}$ & 2.513 & 1.704 & 3.260 & 1.310 & 6.617 & 1.600 \\
\hline $264 \mathrm{~nm}$ & 2.490 & 1.769 & 3.240 & 1.310 & 6.627 & 1.565 \\
\hline
\end{tabular}

Rt: Retention time, Tf: Tailing factor, EMT: Emtricitabine, RIL: Rilpivirine,

TAF: Tenofovir alafenamide

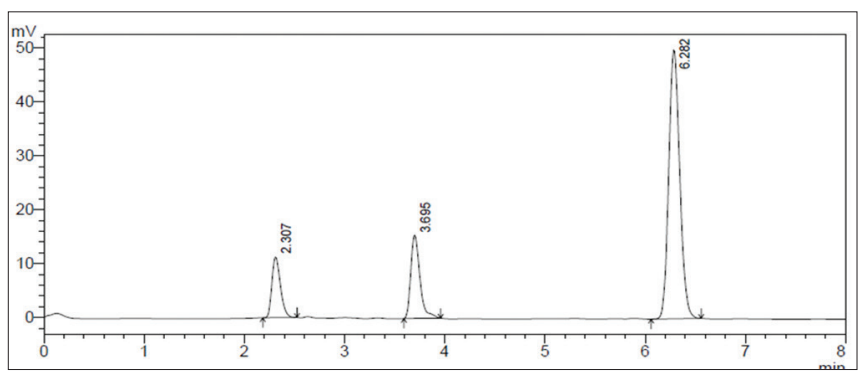

Fig. 7: Acid degradation of emtricitabine, rilpivirine, and tenofovir alafenamide

observed that no interference of degradants with the analyte peak as shown in Figs. 7-11.

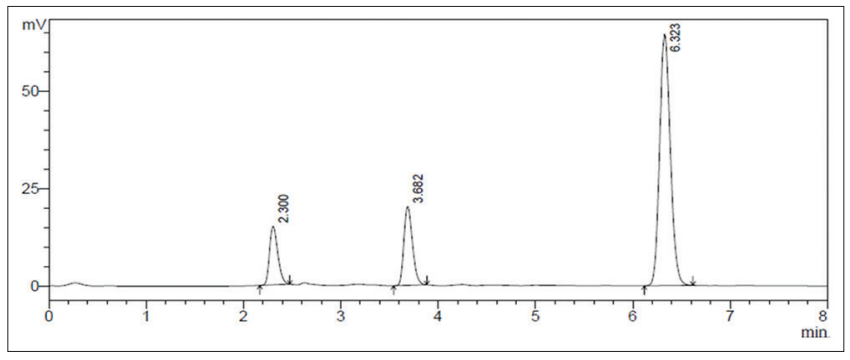

Fig. 8: Base degradation of emtricitabine, rilpivirine, and tenofovir alafenamide

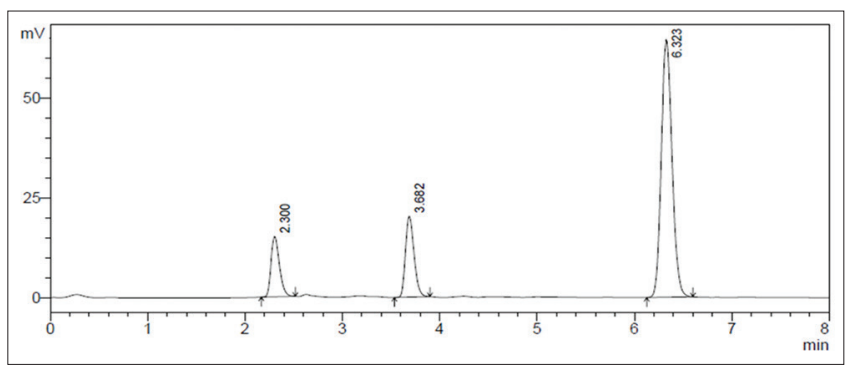

Fig. 9: Thermal degradation of emtricitabine, rilpivirine, and tenofovir alafenamide

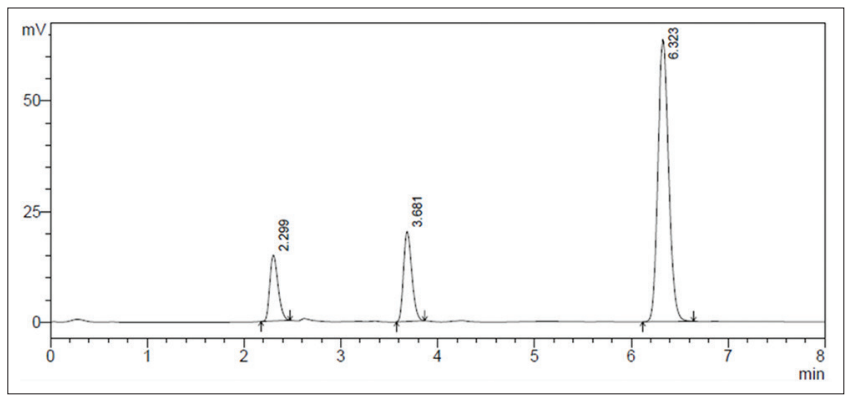

Fig. 10: Photolytic degradation of emtricitabine, rilpivirine, and tenofovir alafenamide

\section{CONCLUSION}

A simple, rapid, accurate, and precise stability-indicating HPLC analytical method had been developed and validated for the routine simultaneous estimation of EMT, RIL, and TAF in API and tablet dosage forms. The RT of EMT, RIL, and TAF using optimum conditions was 2.517, 3.273, and 
Table 9: Stability studies results of EMT, RIL, and TAF

\begin{tabular}{|c|c|c|c|c|c|c|}
\hline \multirow[t]{2}{*}{ Condition } & \multicolumn{2}{|c|}{ EMT } & \multicolumn{2}{|c|}{ RIL } & \multicolumn{2}{|c|}{ TAF } \\
\hline & Area & \% Degraded & Area & \% Degraded & Area & $\%$ Degraded \\
\hline Control & 1078.909 & - & 1088.830 & - & 1748.044 & - \\
\hline Base & 985.109 & 5.08 & 1649.683 & 5.19 & 1224.892 & 5.76 \\
\hline Peroxide & 985.537 & 7.05 & 1641.595 & 6.99 & 1227.220 & 7.55 \\
\hline Thermal & 985.109 & 3.42 & 1649.646 & 2.54 & 1224.892 & 3.59 \\
\hline Photo & 985.023 & 1.85 & 1649.683 & 1.16 & 1224.559 & 2.32 \\
\hline
\end{tabular}

EMT: Emtricitabine, RIL: Rilpivirine, TAF: Tenofovir alafenamide

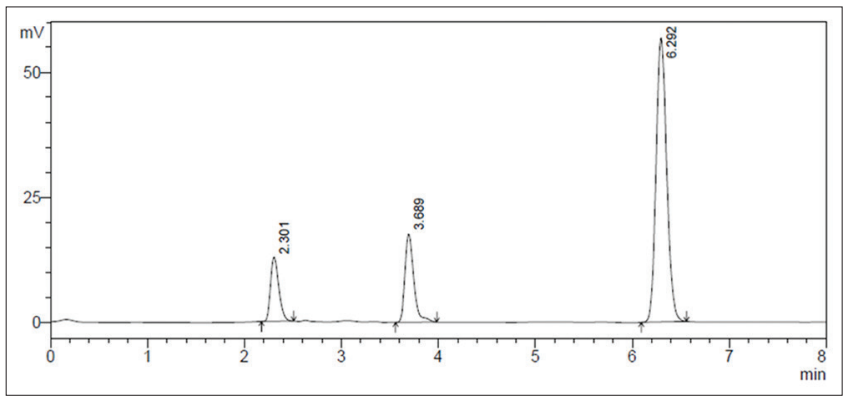

Fig. 11: Peroxide degradation of emtricitabine, rilpivirine, and tenofovir alafenamide

$6.697 \mathrm{~min}$, respectively. The simplicity of the HPLC procedure, the short runtime, and the low volume of injection make this method suitable for quick and routine analysis. The stability indication nature of the analytical method provides confidence to use the developed method in a regulatory environment of the pharmaceutical industry without any further modification.

\section{ACKNOWLEDGMENTS}

Authors are thankful to Hindu College of Pharmacy, Amaravathi Road, Guntur, Andhra Pradesh, India, to provide the infrastructures to pursue the work.

\section{AUTHORS' CONTRIBUTIONS}

All the authors have contributed equally.

\section{CONFLICTS OF INTEREST}

The authors declared that they have no conflicts of interset.

\section{REFERENCES}

1. Seshachalam U, Haribabu B, Chandrasekhar KB. Development and validation of a stability-indicating liquid chromatographic method for determination of emtricitabine and related impurities in drug substance. J Sep Sci 2007;30:999-1004.

2. Joshi M, Nikalje AP, Shahed M, Dehghan M. HPTLC method for the simultaneous estimation of emtricitabine and tenofovir in tablet dosage form. Indian J Pharm Sci 2009;71:95-7.

3. Parthiban C, Bhargavan RM, Sudhakar M. A simple RP-HPLC method for simultaneous estimation of tenofovir disoproxil fumarate and emtricitabine in tablet dosage form. Int Res J Pharm 2011;2:201-3.

4. Sharma T, Mishra N, Swapnak M, Sudam CS, Sankar DG. A validated RP-HPLC method for estimation of tenofovir disoproxil fumarate in bulk and pharmaceutical formulation. Asian J Pharm Clin Res 2012;5:108-10.

5. Ahindita B, Aurobinda P, Amit KM, Dannana GS, Swapna KM, Sudam CS. Development and validation of spectrophotometric methods for determination of emtricitabine and tenofovir disoproxil fumarate in bulk and tablet dosage form. Int J Pharm Tech Res 2011;3:1874-82.

6. Rajesh S, Pooja G. A validated RP-HPLC method for simultaneous estimation of emtricitabine and tenofovir disoproxil fumarate in a tablet dosage form. Eurasian J Anal Chem 2009;4:276-84.

7. Kumar AP, Parthasarathi G, Sudheer AP, Mothi SN, Swamy VH, Rao S. Incidence and risk factors of renal impairment in HIV-1 infected patients receiving tenofovir based antiretroviral therapy in a South Indian hospital. Int J Pharm Sci 2017;9:152-5.

8. Anumolu PD, Anusha K, Sowndarya NS, Sunitha G. Liquid chromatographic quantification of ternary mixture of anti-viral drugs and application to assessment of their tablet dosage form. Int J Pharm Sci 2016;8:237-40.

9. Kavitha KY, Geetha G, Prasad RH, Venkatnarayana R, Subramanian G. Development and validation of RP-HPLC analytical method for simultaneous estimation of emtricitabine, rilpivirine, tenofovir disoproxil fumarate and its pharmaceutical dosage forms. Pharm Globale 2013;4:150-5.

10. Lakshmi PR, Prahlad P, Mastanamma SK, Ravindra N, Rao MV. UPLC separation analysis of emtricitabine, tenofovir, cobisistat and elvitegravir from their degradation products. Int J Pharm Sci 2016;8:362-9

11. Pranitha D, Vanitha C, Francis P, Raja MA, Vardan PV, Surendar M, David B. Simultaneous estimation of emtricitabine, tenofovir disoproxil fumarate and rilpivirine in bulk form by RP-HPLC method. J Pharm Res 2012;5:4600-2.

12. Reddy AP, Teja UC, Sultana SK, Vijayalakshmi M, Nalluri NB. Development and validation of RP-HPLC PDA method for the simultaneous estimation of emtricitabine, tenofovir disoproxil fumarate and rilpivirine hydrochloride in bulk, pharmaceutical dosage forms and in dissolution samples. Indo Am J Pharm Res 2014;4:5226-34.

13. International Conference on Harmonization: ICH: Q2 (R1), Validation of Analytical Procedures: Text and Methodology; 1995.

14. International Conference on Harmonization ICH: Q2B, Analytical Validation-Methodology; 1996. p. 24.

15. International Conference on Harmonization ICH: Q2A, Text on Validation of Analytical Procedure; 1994. p. 22. 